\title{
Study on Wood Cutter Safety System
}

\author{
Omprakash Sonkar ${ }^{1}$, Tilak Ram Sahu ${ }^{2}$, Harsh Jain ${ }^{3}$ \\ ${ }^{1}$ Student of Mechanical Engineering, MATS University Raipur, Chhattisgarh, India \\ ${ }^{2}$ Student of Mechanical Engineering, MATS University Raipur, Chhattisgarh, India \\ ${ }^{3}$ Assistant professor of Mechanical Engineering Department, MATS University Raipur, Chhattisgarh, India
}

\begin{abstract}
The safety devices are very essential devices that should be used in industries or workshops, the danger meets with such type of accident while using wood cutter. In India commonly 15\% people yearly meet with these kind of accidents due to their common human behaviors like tiredness, laziness, sleepiness etc. So to avoid these accidents there is need of device which could be helpful to overcome these accidents. This system consists of a sensor operated disc break which is connected to the shaft of the wood cutter. It is very essential to wear the hand gloves for the sawyer. As sawyer's hand comes in contact with blade cutter. sensor senses the gloves on the hand of sawyer and sends signal to the disc brake to be applied to stop the running cutter blade. So that accident can be prevented and operator can do this job safely.
\end{abstract}

Keywords: saw blade, accident, injury, sensor, disc brake

\section{Introduction}

The wood cutter generally table saw is a commonly used tool in every workshop \& industries. Although there are a variety of models available, all table saws have the same basic design. A flat surface through which a saw blade is attached generally circular in shape. The operator of the saw pushes the item to be cut towards the rapidly spinning blade. The current wood cutter system is not enough to work safely. So there is requirement of wood cutter system. We introducing a wood cutter safety system in which a sensor \& disc brake are used to overcome the accident with the wood cutter.

\section{Types of Safety Devices have used in Wood Cutter}

\subsection{Blade Guard}

A blade guard is clear plastic housing that completely covers the blade when not is used (figure2.1.1). When an item is pushed toward the blade, the blade guard rides up and over the item (fig.2.1.2) and drops down to cover the blade again when the cut is completed. Blade guard prevents contact with the blade from the top, but can not prevent contact to the front of the blade. This is a disadvantage of blade guard.

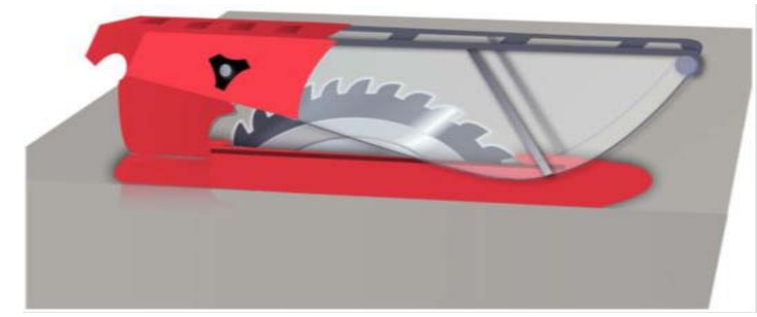

Figure 2.1.1: Table saw with blade guard in place

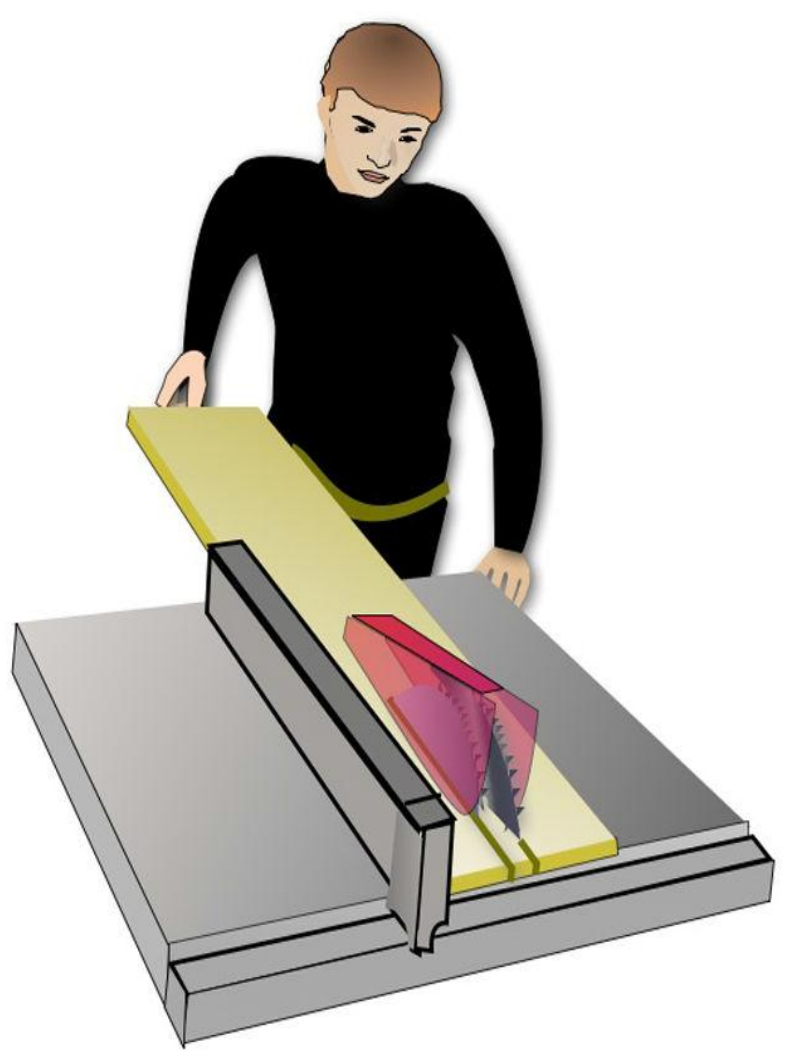

Figure 2.1.2: Blade guard action while cutting. Note that there is no protection from front-approach blade contact

\subsection{Saw stop}

Saw stop is a table saw manufacturer that has developed the first passive safety system for table saws. A saw stop brake cartridge is attached to underside of the table saw. This cartridge applies a small electric charge to saw blade. The charge is continuously monitored and when the contact with a conductive material, such as human finger, lessons the charge the blade is lowered below the table surface and stopped.

Saw stop technology is currently available only on the few models of table saws produced by the saw stop company 


\section{International Journal of Science and Research (IJSR) \\ ISSN (Online): 2319-7064}

Index Copernicus Value (2013): 6.14 | Impact Factor (2015): 6.391

themselves. Other manufacturers have not adopted the technology due to several drawbacks -

a) The technology is expensive.

b)Force required to quickly stop the saw blade damages the blade. There is need to replace the blade each time when the brake is triggered.

\section{Hazards}

\subsection{Safety Hazards at the Time of Operation}

The point of operation is the place where work is performed on the material. This is where the stock is cut. Most woodworking machines use a cutting action. List of Example at the point of operation are followings:-

- Employees can be injured if their hands get too close to the blade, particularly when working on small pieces of stock. The size of the piece dictates that the operator's hand be close to the blade. Accidents can occur when stock unexpectedly moves or when a worker's hand slips.

- Stock can get stuck in a blade and actually pull the operator's hands into the machine.

- Employees can be injured if the machine or its guard is not properly adjusted or maintained.

- Contact also can occur during machine repair or cleaning if care is not taken to de-energize the machine.

\section{2 kickbacks}

Kickbacks occur when a saw traps the stock andthrows it back at the operator. This can happen when the stock twists against the side of the blades or is caught in the teeth. A blade that is not sharpened, or that is set at an incorrect height, can cause kickbacks.

\subsection{Flying chips}

Employees may be exposed to splinters and chips that are flung by the cutting action of woodworking equipment.

\section{Problem Identification}

- The cutter speed is generally very high, which is quite dangerous.

- Damage or accident can be occurring suddenly.

- Human behavior cannot be changed so the chances of accidents are always possible.

- Single accident has ability to give great injury.

\section{Research Methodology}

The research method for the study include on the spot assessment (Segun R.Bello,2010) for injuries in saw mills industries and manuscript (Kevin C.Chung,2013) for the information about the table saw injuries and the safety devices used now a days. We have taken a survey on some saw mills, which are at Timber market Raipur Chhattisgarh for the information about the no. of accidents occurred by the wood cutter and which type of safety devices are used in saw mills. Also we preferred a research paper (P.J. Groot, G.J.
Postma) to take the information about the infrared sensor and the International journal (Asim Rashid, Vol.10, No.4, pp.257.301) for some information regarding the disc brake.

\section{Parts of the System}

This part of the thesis contains the parts and components used in the project. We have used mainly two system parts in the prototype and other parts are the general movable parts like cutter blade, motors and assembly of the wood cutting machine. There are mainly two parts in the wood cutter safety system.

6.1. Motorized disc brake

6.2. Electronic Infrared sensor

\subsection{Motorized disc brake}

This is a general disc brake with its actuating mechanism is operated by motor which is further controlled by an automatic controlling circuit. The disc brake we are using in the model is not similar to the actual disc brake due to its scaled dimensions. Instead of adding disc brake we will make another braking mechanism which will be similar to the disc brake on giving braking effect.

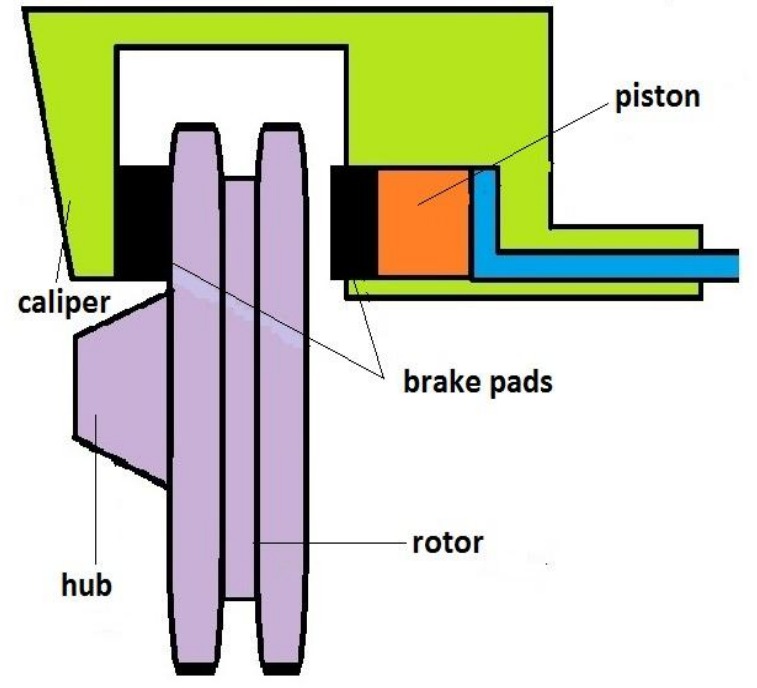

Figure 6.1: Motorized disc brake

A disc brake is a wheel brake which slows rotation of the wheel by the friction caused by pushing brake pads against a brake disc with a set of calipers. The brake disc (or rotor) is usually made of cast iron, but may in some cases be made of composites. This is connected to the wheel. To stop the wheel, friction material in the form of brake pads, mounted on a device called a brake caliper, is forced mechanically, hydraulically, pneumatically or electromagnetically against both sides of the disc. Friction causes the disc and attached wheel to slow or stop. Brakes convert motion to heat, and if the brakes get too hot, they become less effective, a phenomenon known as fade. Disc-style brakes development and use began in England in the 1890s. The first caliper-type automobile disc brake was patented by Frederick William Lanchester in his Birmingham, UK factory in 1902 and used successfully on Lanchester cars. Compared to drum brakes, disc brakes offer better stopping performance, because the disc is more readily cooled. As a consequence discs are less

\section{Volume 5 Issue 4, April 2016}




\section{International Journal of Science and Research (IJSR) \\ ISSN (Online): 2319-7064}

Index Copernicus Value (2013): 6.14 | Impact Factor (2015): 6.391

prone to break fade; and disc brakes recover more quickly from immersion (wet brakes are less effective). Most drum brake designs have at least one leading shoe, which gives a servo-effect. By contrast, a disc brake has no self-servo effect and its braking force is always proportional to the pressure placed on the brake pad by the braking system via any brake servo, braking pedal or lever, this tends to give the driver better "feel" to avoid impending lockup. Drums are also prone to "bell mouthing", and trap worn lining material within the assembly, both causes of various braking problems.

Disc-style brakes development and use began in England in the 1890s. The first caliper-type automobile disc brake was patented by Frederick William Lanchester in his Birmingham factory in 1902 and used successfully on Lanchester cars. However, the limited choice of metals in this period meant that he had to use copper as the braking medium acting on the disc. The poor state of the roads at this time, no more than dusty, rough tracks, meant that the copper wore quickly, making the disc brake system non-viable (as recorded in The Lanchester Legacy). It took another half century for his innovation to be widely adopted.

The 1950 Crosley Hot Shot is often given credit for the first U.S. production disc brakes but the Chrysler Crown Imperial actually had them first as standard equipment at the beginning of the 1949 model year. The Crosley disc was a Goodyear development, a caliper type with ventilated rotor, originally designed for aircraft applications. Only the Hot Shot featured it. Lack of sufficient research caused enormous reliability problems, especially in regions requiring the use of salt on winter roads, such as sticking and corrosion. Drum brake conversions for Hot Shots were quite popular.

The Chrysler four-wheel disc brake system was more complex and expensive than Crosley's, but far more efficient and reliable. It was built by Auto Specialties Manufacturing Company (Ausco) of St. Joseph, Michigan, under patents of inventor H.L. Lambert, and was first tested on a 1939 Plymouth. Unlike the caliper disc, the Ausco-Lambert used twin expanding discs that rubbed against the inner surface of a cast-iron brake drum, which doubled as the brake housing. The discs spread apart to create friction against the inner drum surface through the action of standard wheel cylinders.

\subsection{Electronic IR Sensor}

IR (Infrared) sensors use infrared light to sense any obstacle in front of them and gauge their distance. The commonly used IR sensor have an emitter and a detector. A pulse of infrared light is emitted from the emitter and spreads out in a large arc. If no any obstacle is detected then the IR light continues forever. However, if any obstacle is nearby then the IR light will be reflected and some of it will hit the detector. The detector is able to detect the angle that the IR light arrived back and thus can determine the distance to the obstacle.

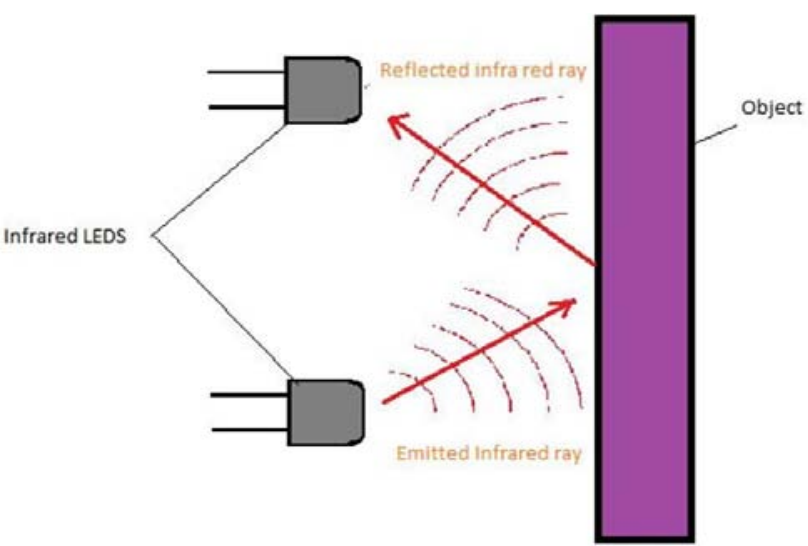

Figure 6.2: Working of IR Sensor

\section{Working of the Project}

- The system works on the quick response method.

- When the cutter is running the sensors are activated when the hand of sawyer's with gloves(generally black) comes very close to the cutter blade, it is sensed by the infrared sensor.

- This sensor signals the controller and controller sends a signal to the disc brake which applies the brake to stop the running blade.

- The motorized disc brake takes very less time for braking.

- The sensitivity of the sensor is lightening fast.

- This makes all the system works quickly in case of accidental contact with blade of cutter.

\section{Expected Results}

- The very first expectation from the projects work is to provide a safe modified and economic improvement in present technology for wealth and health of mankind.

- The system is expected to be quicker.

- This system will be responsive and up-to-date during work.

- The system efficiency is forecast to be useful for future.

- The system will be more accurate after having some tests on it.

- Operator can do his safely.

- Accident rate can be reduced in workshop.

\section{References}

[1] Segun R. Bello and Yahaya Mijinyawa, (2010), Assessment of Injuries in Small Scale Sawmill Industry of South Western Nigeriall, Journal of Scientific Research and Development Volume 12.

[2] Liz Ashby, David Tappin, Dave Moore, (2007), Journal of Centre for Human Factors and Ergonomics, Injury Prevention in Timber Processing Volume 8 No 3.

[3] Bhuvnesh Joshi, (2013), Journal of Mechanical and Civil Engineering, Modification of Disc Brake Using Rotating Brake Pads, Volume 7 No.3. 